\title{
EXPECTATIVAS E CONSOLIDAÇÃO DE EXPERIÊNCIAS DE ALUNOS DO CURSO DE PEDAGOGIA (EAD) PARTICIPANTES DO PROGRAMA DE INICIAÇÃO CIENTÍFICA DO PROJETO PERFIL DAS BRINQUEDOTECAS BRASILEIRAS.
}

\author{
LONDRINA/PR MAIO/2018
}

\author{
LUCIANE BATISTELLA BIANCHINI - UNOPAR - luannbi@hotmail.com \\ BERNADETE LEMA MAZZAFERA - UNOPAR - bernadete.mazzafera@unopar.br \\ PATRÍCIA ALZIRA PROSCÊNCIO - UNOPAR - patricia.proscencio@kroton.com.br \\ LILIAN AMARAL DA SILVA SOUZA - UNOPAR - lilian.ssouza@unopar.br \\ NATALIA GOMES DOS SANTOS - UNOPAR - natalia.gomes@unopar.br \\ TATIANE MOTA SANTOS JARDIM - UNOPAR - tatiane.jardim@kroton.com.br
}

\author{
Tipo: Relato de Experiência Inovadora (EI) \\ Categoria: Pesquisa e Avaliação \\ Setor Educacional: EDUCAÇÃO SUPERIOR
}

\begin{abstract}
RESUMO
Este estudo teve como objetivo descrever a experiência de alunos de graduação, de um curso de Pedagogia-EaD, sobre a participação em um programa de Iniciação Científica do projeto estudo do perfil das brinquedotecas em centros municipais de educação infantil brasileiros. Para responder à questão proposta realizou-se uma pesquisa documental com análise do conteúdo dos relatos dos alunos. Os dados foram categorizados e apresentam-se quantitativamente e qualitativamente. Foram analisados os dados extraídos de uma avaliação diagnóstica disponibilizada no ambiente virtual de aprendizado (AVA) do projeto, que disseram respeito à expectativa inicial dos participantes do programa de Iniciação Científica e às experiências adquiridas ao término do projeto. Inscreveram-se no projeto 157 alunos do curso de pedagogia, tendo 62 inscrições validadas e, desses, 45 responderam à avaliação diagnóstica sobre suas expectativas iniciais e 30 concluintes sobre as experiências adquiridas. Os resultados indicaram que na perspectiva dos alunos o programa de Iniciação Científica no sistema EaD é considerado positivamente, dentre os aspectos destacados temos: a formação pessoal, desenvolvimento da autonomia e aprofundamento teórico sobre o tema pesquisado.
\end{abstract}

Palavras-chave: Pesquisa; Iniciação Científica; Educação a Distância; Alunos; Curso de Pedagogia. 


\section{Introdução}

Muitos alunos ao ingressarem no curso superior têm na Iniciação Científica uma forma de vivenciar a pesquisa. Para Massi e Queiroz (2010, p.2) compreende-se "[...] a Iniciação Científica- IC - como um processo no qual é fornecido o conjunto de conhecimentos indispensáveis para iniciar o jovem nos ritos, técnicas e tradições da ciência".

Mas e no caso da educação a distância, como a experiência em Iniciação Científica pode ser percebida pelos alunos?

Para Suguimoto et al (2017), a participação do aluno de graduação em um programa de Iniciação Científica à distância, possibilita a ampliação da coleta de dados, na medida em que reúne em um mesmo objetivo alunos pesquisadores de diferentes regiões do país, o que contribui com a pesquisa. Ainda permite ao aluno a integração de experiências da sala de aula para outros cenários e contribui com o crescimento pessoal e profissional do mesmo, assim a Iniciação Científica precisa apresentar ações que contemplem de forma indissociável o ensino, a pesquisa e a extensão (SUGUIMOTO et al, 2017).

No curso de pedagogia (locus dos nossos alunos pesquisadores) um dos temas relevantes é o brincar e a formação do brinquedista. Assim a proposta do projeto integrou uma coleta de dados sobre o brincar, a ser realizado pelos alunos participantes de um projeto de pesquisa sobre o tema, e se propôs a contribuir para a formação desses alunos de modo significativo.

O brincar é considerado importante para o desenvolvimento e aprendizagem da criança como um todo (BIANCHINI, 2016, 2009). Wanderlind et al. (2006, p. 265) destaca que os estudos sobre o brincar o consideram como um "[...] comportamento universal, típico da espécie humana; ao mesmo tempo, [...] altamente modulado por características do contexto em que ocorre, o que implica na qualidade da brincadeira e consequentemente no desenvolvimento da criança."

As brinquedotecas em suas diferentes modalidades originam-se da necessidade de proporcionar à criança um local para que ela possa brincar e ter acesso à diversidade de brinquedos, experiências e descobertas que contribuam no seu desenvolvimento e aprendizagem como um todo (BIANCHINI, 2016, 2009).

Desta forma, as brinquedotecas presentes em centros de educação infantil embora 
sejam classificadas como escolares, nem sempre apresentam em sua estruturação (tempo, espaço físico, etc.) um local e ações adequadas para sua proposição junto à criança.

Outro aspecto que também têm levantado reflexões é a formação do profissional que atua nesse contexto, sua capacitação é necessária para que promova enriquecimentos na atividade lúdica infantil. Vectore e Kishimoto (2001, p. 60) abordam que o bom brinquedista como bom mediador "favorece o desenvolvimento das potencialidades de quem brinca; mau mediador, quando, por atitudes autoritárias, rígidas, impede esse mesmo desenvolvimento". Assim justifica-se o projeto que permite verificar os espaços destinados ao brincar nas escolas brasileiras.

\section{Objetivo geral}

Descrever a experiência de alunos de graduação, de um curso de Pedagogia-EaD, sobre a participação em um programa de Iniciação Científica do projeto estudo do perfil das brinquedotecas em centros municipais de educação infantil brasileiros.

\section{Método}

Para responder à questão proposta realizou-se uma pesquisa descritiva ex post facto (acerca de um fenômeno que já ocorreu) com análise do conteúdo dos relatos dos alunos. Foram analisados os dados extraídos de uma avaliação diagnóstica disponibilizada no ambiente virtual de aprendizado (AVA) do projeto, que disseram respeito à expectativa inicial dos participantes do programa de Iniciação Científica e às experiências adquiridas ao término do projeto. Estes responderam, no início do processo de formação do projeto, a pergunta sobre a expectativa em relação ao projeto e depois responderam sobre as experiências adquiridas, após ter concluído o Programa de Iniciação Científica EaD (PIC EaD), para sua vida acadêmica e pessoal. Os dados foram categorizados e apresentam-se qualitativamente e quantitativamente (em relação às respostas que predominaram).

\section{Resultados e Discussões}

Inscreveram-se no programa de Iniciação Científica EaD 157 alunos do curso de 
pedagogia, tendo 62 inscrições validadas e, desses, 45 responderam à avaliação diagnóstica sobre suas expectativas iniciais.

Em relação às expectativas iniciais dos participantes do programa de Iniciação Científica alguns destacaram em sua resposta mais de um aspecto a ser considerado. Nos resultados obtivemos: 39 respostas relacionadas a aprender e construir conhecimentos; 8 respostas quanto à preparação para a pesquisa e publicação; 7 respostas objetivando formação de currículo; 6 deles interessados em experiências que contribuam para a continuidade da vida acadêmica em programas de pós-graduação e, 2 com o intuito de conhecer brinquedotecas escolares. Muitos enfatizaram, ainda, a relevância da oferta de um programa de Iniciação Científica no sistema EaD para sua formação pessoal. Mazzafera e Suguimoto (2016, p. 39-40) abordam que a Iniciação Científica "além de atender aos pressupostos teóricos e legais que representam o ensino superior, possibilita ao estudante, inserido no processo, o desenvolvimento da autonomia intelectual".

Quanto às experiências adquiridas, os trinta concluintes que responderam ao questionamento sobre sua experiência no projeto, atribuíram aspectos positivos no processo vivenciado e destacaram: "ter aprendido mais sobre o brincar"; "que os dados coletados confirmam a literatura sobre o assunto" e "valorizaram a participação no projeto".

Estes dados podem ser exemplificados em mais este relato: "Fazendo uma avaliação da minha participação no projeto, posso dizer que me sinto desafiada a estudar e a refletir sobre minha postura profissional".

Para Erdmann et al (2010, p. 31-32 apud MAZZAFERA; SUGUIMOTO, 2016), a atividade é relevante, já que além de configurar importante etapa da aprendizagem, "os graduandos IC recebem a indiscutível vantagem de formação para o fazer/pesquisar, pelo acompanhamento/desenvolvimento e participação em projetos de pesquisas e experiências acadêmicas oportunizadas por seus orientadores".

Outro ponto que enfatizado foi a necessidade de aprofundamento teórico que os graduandos buscam na IC, visto que um aluno relatou que por meio da participação no projeto é possível vislumbrar o ingresso na pós-graduação stricto sensu. 
Os alunos que buscam participar de um projeto de Iniciação Científica, além de almejar ampliar seus conhecimentos sobre o tema, tem como intuito preparar-se para atuação no campo da pesquisa e enriquecer seu currículo vislumbrando a continuidade da formação acadêmica.

Os alunos, ao término do projeto, destacaram a importância da participação no projeto de Iniciação Científica para a formação acadêmica e profissional, já que, as experiências vivenciadas ampliaram a visão que eles possuíam sobre o brincar e favoreceram a compreensão sobre as mediações que podem ser oportunizadas pelos professores. Eles detectaram ainda que a coleta de dados confirmou as informações obtidas pela literatura da área até o momento. Portanto, a oferta de programas de Iniciação Científica aos alunos da educação a distância, vêm reforçar a efetividade do tripé: ensino-pesquisaextensão, contribuindo significativamente para a formação desse aluno.

\section{Referências:}

BIANCHINI, L. G. B. O brincar e as interações enquanto expressão de desenvolvimento e aprendizagem. 2016. (Desenvolvimento de material didático ou instrucional)

BIANCHINI, L. G. B. Construção do Conhecimento por meio do Brincar. Londrina: Maxi Print, 2009.

MASSI, L.; QUEIROZ, S. L. Estudos sobre iniciação científica no Brasil: uma revisão. Cadernos de pesquisa Fundação Carlos Chagas, v.40 n.139 .2010. p.173-197. Disponível em: http://publicacoes.fcc.org.br/ojs/index.php/cp/issue/view/10>. Acesso em: 24 jun. 2015.

MAZZAFERA, B. L.; SUGUIMOTO, H. Programa de Iniciação Cientifica: influência no aumento quantitativo e qualitativo da produção científica. Política e Gestão Educacional (Online), v. $20, \quad$ p. $38-48, \quad 2016 . \quad$ Disponível em: http://seer.fclar.unesp.br/rpge/article/view/9391/6242. Acesso em: 6 set. 2017.

SUGUIMOTO, H. et al. PIC-EaD: um modelo de iniciação científica para a EaD. In: 23ํㅜ CIAED CONGRESSO INTERNACIONAL ABED DE EDUCAÇÃO A DISTÂNCIA, 23, 2017, Foz de Iguaçu. Anais... Disponível em: www.abed.org.br/hotsite/23-ciaed/pt/anais/ . Acesso em: 29 abr. 2018. 
WANDERLIND, F. et. al. Diferenças de gênero no brincar de crianças pré-escolares e escolares na brinquedoteca. Paidéia (Ribeirão Preto), Ribeirão Preto, v. 16, n. 34, p. 263-273, ago. 2006 Disponível em: http:/www.scielo.br/scielo.php?script=sci_arttext\&pid=S0103-863X2006000200014\&lng =pt\&nrm=iso. Acesso em: 23 abr. 2018.

VECTORE, C.; KISHIMOTO, T. M. Por trás do imaginário infantil: explorando a brinquedoteca. Psicol. Esc. Educ. (Impr.), Campinas, v. 5, n. 2, p. 59-65, dez. 2001. Disponível em: http://www.scielo.br/scielo.php?script=sci_arttext\&pid=S1413-855720010002000007\&lng= pt\&nrm=iso. Acesso em: 23 abr. 2018. 